\title{
INFLUÊNCIA DA MATÉRIA ORGÂNICA E DO AMBIENTE NO CRESCIMENTO E ACÚMULO DE SOLUTOS EM Morinda citrifolia SUBMETIDA À SALINIDADE ${ }^{1}$
}

\author{
MARIA CRISTINA MARTINS RIBEIRO DE SOUZA², CLAUDIVAN FEITOSA DE LACERDA, \\ AIALA VIEIRA AMORIM ${ }^{4}$, ADEMIR SILVA MENEZES $^{5}$
}

RESUMO - O Noni (Morinda citrifolia L.) é uma planta tolerante aos efeitos salinos e alcalinos dos solos e desenvolve-se em regiões de clima seco ou úmido. Apesar da adaptabilidade intercontinental, ainda são poucas as informações sobre sua tolerância aos sais no solo brasileiro. Baseado no exposto, objetivou-se com o presente trabalho avaliar os efeitos da água salina no crescimento inicial do Noni. Para isso, foi conduzido um experimento em vasos de polietileno com capacidade para 20 L, em Sobral, Ceará. O delineamento estatístico adotado foi em blocos ao acaso, disposto no esquema de parcelas subsubdivididas, com 5 repetições. As parcelas foram constituídas pelos ambientes de cultivo (céu aberto e telado), as subparcelas pelos níveis de salinidade da água de irrigação (CEa: 0,$3 ; 1,5 ; 3,0 ; 4,5$ e $6,0 \mathrm{dS} \mathrm{m}^{-1}$ ) e as subsubparcelas foram representadas pela ausência e presença de matéria orgânica. Aos 110 dias após a aplicação dos tratamentos (DAT), avaliaram-se: altura, massa seca da parte aérea (MSPA), da raiz (MSR), total (MST) e área foliar (AF), e aos 90 (DAT) os teores foliares de solutos orgânicos. Todas as variáveis de crescimento estudadas foram afetadas negativamente pela salinidade, sendo que o efeito observado a céu aberto foi mais expressivo do que no ambiente telado. A matéria orgânica não teve efeito atenuante sobre os efeitos deletérios da salinidade em plantas de noni. $\mathrm{O}$ acúmulo de prolina mostrou-se um sinalizador de dano causado pelo estresse, visto que os maiores acúmulos ocorreram nas plantas que sofreram maiores reduções no crescimento.

Termos para indexação: Noni, massa seca, carboidrato, compostos orgânicos.

\section{INFLUENCE OF ORGANIC MATTER AND THE ENVIRONMENT IN GROWTH AND IN SOLUTE ACCUMULATION IN Morinda citrifolia SUBMITTED TO SALINITY}

\begin{abstract}
Noni (Morinda citrifolia L.) is a plant tolerant to the effects of saline and alkaline soils and grows in dry or moist climates. Despite the intercontinental adaptability, in Brazil there is little information about its tolerance to soil salinity. The objective of the present study was to evaluate the effects of saline water on the growth of Noni. For this an experiment was conducted in polyethylene pots with a capacity of $20 \mathrm{~L}$, in Sobral, Ceará. The statistical design was a randomized block design arranged in split plot scheme, with 5 repetitions. The plots consisted of the cultivation environments (open sky and greenhouse), the subplots by salinity levels of irrigation water (ECw: $0.3,1.5,3.0,4.5$ and $6.0 \mathrm{dS} \mathrm{m}^{-1}$ ), and the subsubplots were represented by the absence and presence of organic matter. At 110 days after treatment (DAT), the following variables were evaluated: height, shoot dry mass (SDM), root dry mass (RDM), total dry mass (TDM) and leaf area (LA) and at 90 DAT organic solutes in the leaf. All variables were negatively affected by salinity and the effect observed in the open environment was more intense than under greenhouse conditions. The organic matter had no effect on mitigating the deleterious effects of salinity in plants of noni. The accumulation of proline was found to be a sign of stress damage, since the highest accumulation of this solute was observed in plants that experienced greater reductions in growth.

Index terms: Noni, dry mass, carbohydrate, organic compounds.

\footnotetext{
'(Trabalho 319-13). Recebido em: 16-09-2013. Aceito para publicação em: 06-05-2014.

${ }^{2}$ Professora do Instituto Federal de Educação, Ciência e Tecnologia do Ceará - Campus Sobral, Sobral, CE, E-mail: cristina2009@ ifce.edu.br

${ }^{3}$ Professor Associado do Departamento de Engenharia Agrícola da Universidade Federal do Ceará, Campus Pici, Fortaleza, CE, E-mail: cfeitosa@ufc.br

${ }^{4}$ Professora do Instituto de Desenvolvimento Rural da Universidade da Integração Internacional da Lusofonia Afro-Brasileira (UNILAB), Redenção-CE. E-mail: aialaamorim@unilab.edu.br (*Autor para correspondência)

Graduando em Tecnologia de Irrigação e Drenagem, do Instituto Federal de Educação, Ciência e Tecnologia do Ceará - Campus Sobral, CE, E-mail: amenezzes@gmail.com
} 


\section{INTRODUÇÃO}

Produtos naturais e ervas da medicina popular têm sido usados há séculos por várias culturas em todo o mundo, sendo que cientistas e profissionais de várias áreas têm demonstrado interesse crescente neste assunto, a fim de reconhecer os verdadeiros benefícios que os vegetais podem fornecer. Entre as plantas medicinais, a Morinda citrifolia L. (noni), descoberta pelos ancestrais dos polinésios, é um dos vegetais mais populares e tradicionais de que se utilizam várias partes, as quais apresentam uma gama de efeitos terapêuticos, incluindo os antibacterianos, antivirais, antifúngicos, antitumorais, analgésico e anti-inflamatórios (CHAN-BLANCO et al., 2006). Costa et al. (2013) relatam que frutas exóticas, como o Noni, têm ganhado cada vez mais espaço, tanto pela busca de benefícios que estas oferecem, como pela procura por diferentes tipos de fontes alimentares.

Além das propriedades terapêuticas, o noni destaca-se por suas habilidades às mais diversas situações de clima, solo e estresses ambientais (NUNES et al., 2009). Dentre os estresses ambientais, destaca-se a salinidade, e segundo Abdelfattah et al. (2009), estima-se que, no mundo, cerca de um bilhão de hectares, o que representa cerca de 7\% da extensão da terra, são afetados por sais. Para Amorim et al. (2010), o excesso de sais pode perturbar as funções fisiológicas e bioquímicas das plantas, resultando em distúrbios nas relações hídricas e alterações na absorção e na utilização de nutrientes essenciais para as plantas. No que se refere ao noni, apesar da adaptabilidade intercontinental, as informações sobre plantios comerciais de noni no Brasil, sua tolerância aos sais do solo e/ou água de irrigação ainda são excassas (NUNES et al., 2009).

A redução no crescimento e na produtividade é um dos principais efeitos observados nas plantas cultivadas sob estresse salino (HUANG et al., 2012). Um dos mecanismos utilizados pelos vegetais para minimizar os efeitos deletérios desse estresse é balancear os potenciais osmóticos, entre o citoplasma e o vacúolo, produzindo mais compostos orgânicos solúveis, como: carboidratos, $\mathrm{N}$-aminossolúveis e prolina (MUNNS et al., 2002). Outra alternativa é o emprego de substâncias que reduzam a intensidade dos efeitos danosos dos sais, possibilitando o uso de águas salinas durante o crescimento das plantas. Um exemplo disso foi observado por Cavalcante et al. (2010), ao detectar a ação atenuante do biofertilizante bovino no crescimento inicial de goiabeira paluma (Psidium guajava) submetida à salinidade da água de irrigação.
O objetivo deste trabalho foi avaliar se o uso da matéria orgânica e o cultivo em diferentes ambientes podem alterar as respostas de crescimento e produção de solutos orgânicos em Morinda citrifolia L. sob condições de estresse salino.

\section{MATERIAL E MÉTODOS}

\section{Localização do experimento}

O experimento foi conduzido em dois ambientes: um telado preto revestido na parte superior e lateral com sombreamento de $50 \%$ e outro a céu aberto, em uma área pertencente à prefeitura municipal de Sobral, Ceará, no período de maio de 2011 a dezembro de 2011. Esta área tem uma localização determinada pelas coordenadas geográficas de $3^{\circ} 41^{\prime} 10^{\prime \prime}$ de latitude sul e $40^{\circ} 20^{\prime} 59^{\prime \prime}$ de longitude oeste, com altitude média de $70 \mathrm{~m}$. Segundo a classificação de Köppen, essa região é de clima do tipo BSw'h', por possuir um clima tipicamente tropical quente, com chuvas de verão e temperatura máxima variando entre $36^{\circ} \mathrm{C}$ em outubro e $31,2^{\circ} \mathrm{C}$ em maio, e mínima entre $23,2^{\circ} \mathrm{C}$ em dezembro e $21^{\circ} \mathrm{C}$ em julho, com precipitação pluviométrica anual de $833 \mathrm{~mm}$. No período experimental, a precipitação média foi de 39,52 $\mathrm{mm}$, e as médias das temperaturas máxima e mínima foram, respectivamente, de $36,2{ }^{\circ} \mathrm{C}$ e $21,6{ }^{\circ} \mathrm{C}$.

\section{Delineamento experimental}

O delineamento estatístico adotado foi em blocos ao acaso, disposto no esquema de parcelas subsubdivididas, com 5 repetições. As parcelas foram constituídas pelos ambientes de cultivo (céu aberto e telado), as subparcelas pelos níveis de salinidade da água de irrigação (CEa: 0,3;1,5; 3,0; 4,5 e 6,0 $\mathrm{dS} \mathrm{m}^{-1}$ ) e as subsubparcelas foram representadas pela ausência e presença de matéria orgânica. A combinação desses fatores resultou em 20 diferentes tratamentos, sendo que cada repetição foi constituída de três plantas (uma planta por vaso), totalizando 300 vasos.

\section{Preparo das mudas}

As mudas foram adquiridas por semeadura em bandejas com 200 células e completas com o seguinte substrato: $50 \%$ de areia lavada $+50 \%$ de esterco de gado curtido e irrigadas diariamente com água de $\mathrm{CEa}=0,3 \mathrm{dS} \mathrm{m} \mathrm{m}^{-1}$ (Testemunha). Aos 60 dias após a semeadura, foram selecionadas as mudas mais vigorosas, que foram transplantadas para sacos de polietileno, nas dimensões de $15 \times 28 \mathrm{~cm}$, com uma mistura de esterco de gado (curtido) e solo, nas proporções de 1:1, respectivamente. Para cada $20 \mathrm{~L}$ 
desta mistura, acrescentaram-se $500 \mathrm{~g}$ da formulação 4:14:8 (NPK), utilizando, respectivamente, como fontes: sulfato de amônia, superfosfato simples e cloreto de potássio. As mudas foram irrigadas diariamente com água de condutividade elétrica $0,3 \mathrm{dS} \mathrm{m}^{-1}$ até atingirem 4 a 6 pares de folhas para o transplantio.

Para o transplantio, utilizaram-se vasos de polietileno devidamente identificados, com capacidade de $20 \mathrm{~L}$, no fundo dos quais foi utilizada uma camada de aproximadamente $2 \mathrm{~cm}$ de brita para facilitar a drenagem. Os vasos foram preparados, colocando-se $50 \%$ de solo, e nos tratamentos com matéria orgânica, foi incorporado $50 \%$ de composto orgânico constituído por esterco de gado e restos de plantas. As características físicas e químicas do substrato utilizado estão demonstradas na Tabela 1.

Com o intuito de corrigir eventuais carências nutricionais do substrato, foram aplicados, em cada vaso, $0,5 \mathrm{~g}$ de ureia, $1,0 \mathrm{~g}$ de superfosfato simples e $0,5 \mathrm{~g}$ de cloreto de potássio. A adubação, iniciada a partir da aplicação dos tratamentos, foi realizada aos 30; 45 e 60 dias após o estabelecimento das plantas.

\section{Preparo das soluções e aplicação dos tratamentos}

Para atingir os níveis de condutividade elétrica da água de irrigação CEa desejados, utilizaram-se diferentes quantidades de sais de $\mathrm{NaCl}$, $\mathrm{CaCl}_{2} \cdot 2 \mathrm{H}_{2} \mathrm{O}$ e $\mathrm{MgCl}_{2} \cdot 6 \mathrm{H}_{2} \mathrm{O}$, na proporção equivalente de $7: 2: 1$, obedecendo-se à relação entre CEa e a concentração (mmolc $\mathrm{L}^{-1}=\mathrm{CE}$ x 10). As quantidades dos compostos químicos dos sais calculados foram preparadas no laboratório de Análise de Solo e Água para Irrigação, do Instituto Federal de Ciência e Tecnologia - IFCE - Câmpus Sobral, e por ocasião da irrigação eram diluídos com água da testemunha $\left(0,3 \mathrm{dS} \mathrm{m}^{-1}\right)$, num balde com capacidade para 60 L. Após a diluição, procedia-se à leitura da CE das amostras das águas salinas com a finalidade de aferir os diferentes níveis desejados.

Os tratamentos salinos foram aplicados em dias alternados, sendo iniciados aos 5 DAT, e o volume de solução aplicado às plantas foi de acordo com o princípio do lisímetro de drenagem, mantendo-se o substrato na capacidade de campo e adicionando-se frações de lixiviação de $20 \%$ para prevenir o acúmulo excessivo de sais. A aplicação da água foi feita de forma localizada, de modo a evitar seu contato direto com as folhas.
Determinação das variáveis de crescimento

Aos 110 dias após a aplicação dos tratamentos (DAT), foram feitas medições de altura, massa seca da parte aérea (MSPA), da raiz (MSR), massa seca total (MST) e área foliar (AF). A altura foi determinada com o auxílio de uma régua graduada, desde o colo da planta até a inserção da última folha. Para a área foliar, utilizou-se um medidor de superfície (LI - 3100, Área Meter, Li-Cor., Inc., Lincoln, Nebraska, USA).

A massa seca da parte área e do sistema radicular foi obtida a partir da separação das folhas, do caule e das raízes, com o auxílio de estilete. As raízes separadas foram logo lavadas com água destilada para retirar resíduos de solo aderidos. Em seguida, foram colocadas em sacos de papel previamente identificados e postos para secar em estufa de circulação de ar forçado, a $65^{\circ} \mathrm{C}$, durante 72 horas, onde, após atingirem peso constante, procedeu-se à pesagem em balança analítica. A massa seca total foi obtida através do somatório da massa seca da parte aérea e das raízes.

\section{Determinação de solutos orgânicos}

Folhas coletadas aos 90 DAT foram liofilizadas, maceradas em gral de porcelana, em presença de nitrogênio líquido e armazenadas para posterior análise de carboidratos solúveis (DUBOIS, et al., 1956), proteínas (BRADFORD, 1976), prolina (BATES et al., 1973) e N-aminossolúveis (YEMM; WILLS, 1954).

\section{Análises estatísticas}

Os resultados foram analisados estatisticamente utilizando-se o programa "ASSISTAT 7.6 BETA". Os dados das variáveis analisadas foram submetidos à análise de variância, e posteriormente, quando significativos pelo teste $\mathrm{F}$, submetidos ao teste de médias de Tukey com $\mathrm{P}<0,05$ (para ambiente e matéria orgânica) e à análise de regressão (níveis de salinidade). Na análise de regressão, as equações foram selecionadas com base na significância dos coeficientes de regressão, a 1\% e 5\% de probabilidade pelo teste $\mathrm{F}$, e com maior coeficiente de determinação.

\section{RESULTADOS E DISCUSSÃO}

\section{Variáveis de crescimento}

De forma geral, através do resumo da análise de variância dos dados de crescimento de Morinda citrifolia, observa-se que houve efeito significativo pelo teste $\mathrm{F}(\mathrm{p}<0,01$ e $\mathrm{p}<0,05)$ dos fatores isolados: ambiente, salinidade e matéria orgânica, com exceção 
da área foliar e da massa seca da raiz, que não foram influenciadas significativamente pelos fatores ambiente e matéria orgânica, respectivamente. Analisando as interações duplas, verifica-se que houve efeito significativo da interação ambiente versus salinidade na MSPA, MSR e MST, enquanto a interação ambiente e matéria orgânica influenciou na altura e MST. Por outro lado, quando se observa a interação entre os três fatores estudados, nenhuma variável foi afetada significativamente (Tabela 2).

$\mathrm{O}$ efeito conjunto dos fatores proporcionou um decréscimo linear de todas as variáveis de crescimento, em função do aumento nos níveis de salinidade da água de irrigação (Figura 1). Comparando o tratamento-testemunha $\left(0,3 \mathrm{dS} \mathrm{m}^{-1}\right)$ com o maior nível de salinidade, observa-se redução linear de $29 \%$ na altura e $42 \%$ na área foliar (Figuras 1A e 1D).

O efeito da interação ambiente versus níveis de salinidade pode ser observado nas figuras 1B, $1 \mathrm{C}$ e 1D. Além disso, pode-se verificar que, apesar de os maiores valores das variáveis de crescimento serem em plantas submetidas à condição de céu aberto, nestas, as perdas no crescimento foram mais acentuadas quando comparadas às plantas cultivadas em telado (Figuras 1B, C e D). Para MSPA, MSR e MST das plantas cultivadas a céu aberto, as maiores reduções foram, respectivamente, de $56 \%, 63 \%$ e $60 \%$, enquanto no ambiente telado essas reduções foram de $22 \%, 29 \%$ e $24 \%$, comparando-se as plantas irrigadas com a água de mais baixa e mais alta salinidade.

Esses resultados assemelham-se aos encontrados por Figueiredo et al. (2006) e Nazário et al. (2010), que verificaram reduções nas variáveis de crescimento em plantas da mesma família do noni, cultivadas em ambiente salino. Por outro lado, Nunes et al. (2009) verificaram em plantas de noni que esse efeito negativo da salinidade no crescimento de plantas pode ser minimizado com a utilização de biofertilizante. Para Nivas et al. (2011), a tolerância à salinidade depende da espécie, visto que, ao estudarem o efeito desse estresse em duas espécies do gênero Morinda (Morinda citrifolia e Morinda pubescens), verificaram que a primeira é mais tolerante que a segunda.

Respostas no crescimento das plantas podem estar associadas aos mecanismos de adaptação das espécies ao ambiente de cultivo. Isso pode ser observado no presente trabalho, pois as plantas cultivadas em telado, apesar de terem menores valores nas variáveis de crescimento, sofreram menos com a salinidade do que as plantas cultivadas a céu aberto (Figura1B, C e D). Melo e Cunha (2008) destacaram que as espécies vegetais que crescem em ambientes com luminosidade diferente daquela a que não está adaptada, necessitam ajustar com eficácia suas respostas fisiológicas a fim de aumentar a aquisição de recursos nesse ambiente. Já para Martins et al. (2009), as variações na intensidade da luz proporcionam diversas modificações relacionadas à produção de biomassa e formação de estruturas produtoras de metabólitos secundários.

Quando se considera a média de todas as plantas que receberam ou não matéria orgânica (Tabela 3), observa-se que a presença de matéria orgânica só teve efeito positivo na altura e AF que tiveram valores médios de $34,7 \mathrm{~cm}$ e $3.250,034$ $\mathrm{cm}^{2}$, respectivamente. Apesar de as plantas com matéria orgânica terem produzido maior quantidade de folhas a MSPA e MST foi maior nas plantas sem matéria orgânica, indicando alteração na partição de matéria seca causada por este fator. Segundo Cha-um e Kirdmanee (2011), a matéria orgânica aplicada em solo com problemas de sais, além de estabilizar a estrutura física do solo, reduz a formação de crosta superficial, o que possibilita melhor taxa de infiltração e respiração das raízes e assim promovendo melhor crescimento das plantas. Para Cavalcante et al. (2009), a utilização de insumos orgânicos (biofertilizantes) pode estimular a liberação de substâncias húmicas, causando aumento expressivo no crescimento vegetativo das plantas.

\section{Solutos Orgânicos}

Considerando os fatores isolados, observa-se, através do resumo da análise de variância dos dados de solutos orgânicos de Morinda citrifolia, que os carboidratos solúveis, $\mathrm{N}$-aminossolúveis e proteínas só sofreram influência significativa pelo teste $\mathrm{F}$ ( $\mathrm{p}$ $<0,01$ e p $<0,05$ ) do ambiente (Tabela 4). Por outro lado, a prolina foi influenciada pela salinidade e matéria orgânica. Quando se observam as interações entre os fatores estudados, nenhuma variável sofreu influência significativa, com exceção da interação ambiente versus sal que influenciou nos teores de prolina, a interação ambiente versus matéria orgânica que influenciou nos $\mathrm{N}$-aminossolúveis e a interação salinidade versus matéria orgânica que influenciou nos carboidratos (Tabela 4).

$\mathrm{Na}$ Figura 2, constata-se que a interação ambiente versus níveis de sais exerceu efeito significativo sobre o teor de prolina aos 90 dias depois da aplicação dos tratamentos. Comparando o menor com o maior nível de salinidade da água, o aumento deste soluto orgânico foi mais expressivo nas plantas cultivadas a céu aberto (56\%) quando comparadas 
às plantas cultivadas em telado $(21 \%)$. Estes dados evidenciam que a prolina se mostra um sinalizador do dano causado pelo estresse (LACERDA et al., 2003), visto que as plantas cultivadas a céu aberto tiveram maiores reduções no crescimento (Figura 1), ou seja, sofreram mais com o estresse salino.

Divergindo dos resultados do presente trabalho, Kavi Kishor et al. (2005) afirmaram que a prolina é um aminoácido que, quando acumulado, atua como depósito de energia e reserva de carbono e nitrogênio utilizado pela planta no processo de restabelecimento após o estresse. Para Blanco et al. (2008), o nível de prolina aumenta sob estresse salino e, com o tempo de exposição das plantas, à salinidade, o que sugere um papel protetor deste soluto orgânico.

Na Tabela 5, constata-se o efeito do fator isolado ambiente sobre os teores de carboidratos, $\mathrm{N}$-aminossolúveis, proteína e prolina. Observase que, quando as plantas foram cultivadas a céu aberto, apresentaram um aumento de 81,27 ( $\mu \mathrm{mol}$ $\left.\mathrm{g}^{-1} \mathrm{MS}\right)$ e 3,90 (mg MS), respectivamente, para carboidratos e proteínas quando comparadas com as plantas cultivadas em telado, enquanto os teores de de N-aminossolúveis foram maiores nas plantas cultivadas no telado. Por outro lado, nos teores de prolina, não foram observadas diferenças estatísticas entre os ambientes de cultivo.

TABELA 1 - Características físicas e químicas do substrato utilizado no experimento. Sobral-CE.

\begin{tabular}{|c|c|c|}
\hline & Tratamento sem Matéria Orgânica & Tratamento com Matéria Orgânica \\
\hline Classificação Textural & Areia & Areia \\
\hline $\mathrm{CE}\left(\mathrm{dS} \mathrm{m} \mathrm{m}^{-1}\right)$ & 0,14 & 0,16 \\
\hline $\mathrm{Ca}^{+2}\left(\mathrm{mmol}_{\mathrm{c}} \mathrm{dm}^{-3}\right)$ & 42,0 & 40,0 \\
\hline $\mathrm{Mg}^{2+}\left(\mathrm{mmol}_{\mathrm{c}} \mathrm{dm}^{-3}\right)$ & 6,0 & 37,0 \\
\hline $\mathrm{Na}^{+}\left(\mathrm{mmol}_{\mathrm{c}} \mathrm{dm}^{-3}\right)$ & 1,2 & 1,6 \\
\hline $\mathrm{K}^{+}\left(\mathrm{mmol}_{\mathrm{c}} \mathrm{dm}^{-3}\right)$ & 1,47 & 24,07 \\
\hline $\mathrm{H}^{+}+\mathrm{Al}^{3+}\left(\mathrm{mmol}_{\mathrm{c}} \mathrm{dm}^{-3}\right)$ & 23,93 & 28,88 \\
\hline Matéria Orgânica $\left(\mathrm{g} \mathrm{kg}^{-1}\right)$ & 3,72 & 24,72 \\
\hline
\end{tabular}

TABELA 2 - Resumo da análise de variância para a altura de planta, massa seca da parte aérea (MSPA), da raiz (MSR), total (MST) e área foliar de Morinda citrifolia cultivadas em dois ambientes, sob diferentes níveis de sais na água de irrigação, na presença e ausência de matéria orgânica Sobral-CE. 2011.

\begin{tabular}{ccccccc}
\hline \multirow{2}{*}{ Fontes de Variação } & \multirow{2}{*}{ GL } & \multicolumn{5}{c}{ Quadrado Médio } \\
\cline { 3 - 7 } Blocos & 4 & Altura & MSPA & MSR & MST & AF \\
Amb (a) & 1 & $534,55^{\mathrm{ns}}$ & $97,91^{\mathrm{ns}}$ & $17,52^{\mathrm{ns}}$ & $197,62^{\mathrm{ns}}$ & $1.153 .990,42^{\mathrm{ns}}$ \\
Resíduo (a) & 4 & $23,712,70^{* *}$ & $516,01^{* *}$ & $8.347,58^{* *}$ & $6.081 .343,41^{\mathrm{ns}}$ \\
Sal(b) & 4 & $434,33^{* *}$ & $460,5^{* *}$ & $158,09 * *$ & $1.144,31^{* *}$ & $5.858 .386,24^{* *}$ \\
Amb x Sal & 4 & $16,47^{\mathrm{ns}}$ & $274,93^{* *}$ & $94,30^{* *}$ & $676.17^{* *}$ & $1.031 .568,37^{\mathrm{ns}}$ \\
Resíduo (b) & 32 & 13,39 & 30,03 & 4,76 & 53,07 & $888.215,85$ \\
MO (c) & 1 & $49,42^{*}$ & $200,9^{* *}$ & $18,97^{\mathrm{ns}}$ & $96,41^{* *}$ & $24.906 .168,20^{* *}$ \\
Amb x MO & 1 & $6,21^{* *}$ & $4,54^{\mathrm{ns}}$ & $16,03^{\mathrm{ns}}$ & $37,65^{* *}$ & $582.465,08^{\mathrm{ns}}$ \\
Sal x MO & 4 & $2,62^{\mathrm{ns}}$ & $5,24^{\mathrm{ns}}$ & 6,09 ns & $1.72^{\mathrm{ns}}$ & $740.627,88^{\mathrm{ns}}$ \\
Amb x Sal x MO & 4 & $9,06^{\mathrm{ns}}$ & $1,51^{\mathrm{ns}}$ & $0,90^{\mathrm{ns}}$ & $0,91^{\mathrm{ns}}$ & $748.659,92^{\mathrm{ns}}$ \\
Resíduo (c) & 40 & 6,77 & 2,08 & 4,92 & 4,01 & $855.998,46$ \\
CV(a) & - & 14,35 & 19,75 & 32,44 & 20,36 & 37,30 \\
CV(b) & - & 10,77 & 25,08 & 26,01 & 24,09 & 34,26 \\
CV(c) & - & 7,65 & 6,61 & 26,43 & 6,62 & 33,63
\end{tabular}

**** e ns - significativo a $1 \%$ e a $5 \%$ de probabilidade e não significativo pelo teste $\mathrm{F}$, respectivamente. GL- grau de liberdade. CV coeficiente de variação em porcentagem. 
TABELA 3 - Dados médios de altura, massa seca da parte aérea (MSPA), da raiz (MSR), total (MST) e área foliar (AF) de Morinda citrifolia em função da presença e ausência de matéria orgânica, aos 110 dias após o início do experimento. Sobral- CE, 2011.

\begin{tabular}{cccccc}
\hline Substrato/ Variáveis & Altura $(\mathrm{cm})$ & MSPA $(\mathrm{g})$ & MSR $(\mathrm{g})$ & MST $(\mathrm{g})$ & $\mathrm{AF}\left(\mathrm{cm}^{2}\right)$ \\
\hline Ausência de MO & $33,3 \mathrm{~b}$ & $23,2 \mathrm{a}$ & $7,96 \mathrm{a}$ & $31,2 \mathrm{a}$ & $2.251,912 \mathrm{~b}$ \\
Presença de MO & $34,7 \mathrm{a}$ & $20,4 \mathrm{~b}$ & $8,83 \mathrm{a}$ & $29,3 \mathrm{~b}$ & $3.250,034 \mathrm{a}$ \\
\hline
\end{tabular}

Médias seguidas da mesma letra não diferem pelo teste de Tukey.

TABELA 4 - Resumo da análise de variância dos teores foliares de carboidratos, N-aminossolúveis, proteína e prolina de Morinda citrifolia cultivadas em dois ambientes, sob diferentes níveis de sais na água de irrigação, na presença e ausência de matéria orgânica Sobral-CE. 2011.

\begin{tabular}{|c|c|c|c|c|c|}
\hline \multirow{2}{*}{ Fontes de Variação } & \multirow{2}{*}{ GL } & \multicolumn{4}{|c|}{ Quadrado Médio } \\
\hline & & Carboidratos & N-aminossolúveis & Proteína & Prolina \\
\hline Bloco & 4 & $3.873,63^{\mathrm{ns}}$ & $82,49^{\text {ns }}$ & $1,15^{\mathrm{ns}}$ & $117,87^{\mathrm{ns}}$ \\
\hline $\mathrm{Amb}(\mathrm{a})$ & 1 & $132.102,32 * *$ & $588,13^{*}$ & $304,41 * *$ & $23,48^{\mathrm{ns}}$ \\
\hline Resíduo (a) & 4 & 1216,63 & 22,76 & 1,16 & 59,72 \\
\hline Sal (b) & 4 & $736,38^{\mathrm{ns}}$ & $146,10^{\mathrm{ns}}$ & $3,06^{\mathrm{ns}}$ & $61,10 * *$ \\
\hline Amb x Sal & 4 & $407,74^{\mathrm{ns}}$ & $49,44^{\mathrm{ns}}$ & $2,96^{\mathrm{ns}}$ & $54,9, *$ \\
\hline Resíduo (b) & 32 & $1.276,91$ & 119,18 & 3,81 & 18,09 \\
\hline $\mathrm{MO}(\mathrm{c})$ & 1 & $139,36^{\text {ns }}$ & $144,16^{\mathrm{ns}}$ & $0,89^{\text {ns }}$ & $412,86^{* *}$ \\
\hline Amb x MO & 1 & $5.737,51^{\mathrm{ns}}$ & $521,81 *$ & $0,66^{\mathrm{ns}}$ & $25,39^{\mathrm{ns}}$ \\
\hline Sal x MO & 4 & $69,32 * *$ & $61,012^{\text {ns }}$ & $2,01^{\mathrm{ns}}$ & $5,46^{\mathrm{ns}}$ \\
\hline Amb x Sal x MO & 4 & $1.400,69^{\mathrm{ns}}$ & $228,56^{\mathrm{ns}}$ & $2,02^{\mathrm{ns}}$ & $10,66^{\mathrm{ns}}$ \\
\hline Resíduo (c) & 40 & $1.658,67$ & 95,94 & 3,26 & 12,62 \\
\hline $\mathrm{CV}(\mathrm{a})$ & - & 19,96 & 45,57 & 53.50 & 82,48 \\
\hline $\mathrm{CV}(\mathrm{b})$ & - & 20,45 & 104,28 & 96.87 & 45,40 \\
\hline $\mathrm{CV}(\mathrm{c})$ & - & 23,30 & 93,57 & 89.67 & 37,92 \\
\hline
\end{tabular}

**,* $\mathrm{e}^{\text {ns }}$ - significativo a $1 \%$ e a $5 \%$ de probabilidade e não significativo pelo teste $\mathrm{F}$, respectivamente. GL- grau de liberdade. CV coeficiente de variação em porcentagem.

TABELA 5 - Dados médios de carboidratos, N-aminossolúveis, Proteína e Prolina de Morinda citrifolia em função de dois ambientes de cultivo, céu aberto e telado, aos 90 dias após o início do experimento. Sobral- CE, 2011.

\begin{tabular}{ccccc}
\hline Ambiente/ Variáveis & $\begin{array}{c}\text { Carboidratos } \\
\left(\mu \mathrm{mol} \mathrm{g}{ }^{-1} \mathrm{MS}\right)\end{array}$ & $\begin{array}{c}\text { N-aminossolúveis } \\
\left(\mu \mathrm{mol} \mathrm{g} \mathrm{MS}^{-1}\right)\end{array}$ & $\begin{array}{c}\text { Proteína } \\
(\mathrm{mg} \mathrm{MS})\end{array}$ & $\begin{array}{c}\text { Prolina } \\
\left(\mu \mathrm{mol} \mathrm{g}^{-1} \mathrm{MS}\right)\end{array}$ \\
\hline Céu Aberto & $215,41 \mathrm{a}$ & $7,76 \mathrm{~b}$ & $3,96 \mathrm{a}$ & $9,91 \mathrm{a}$ \\
Telado & $134,14 \mathrm{~b}$ & $13,18 \mathrm{a}$ & $0,06 \mathrm{~b}$ & $8,83 \mathrm{a}$ \\
\hline
\end{tabular}

Médias seguidas da mesma letra não diferem pelo teste de Tukey. 

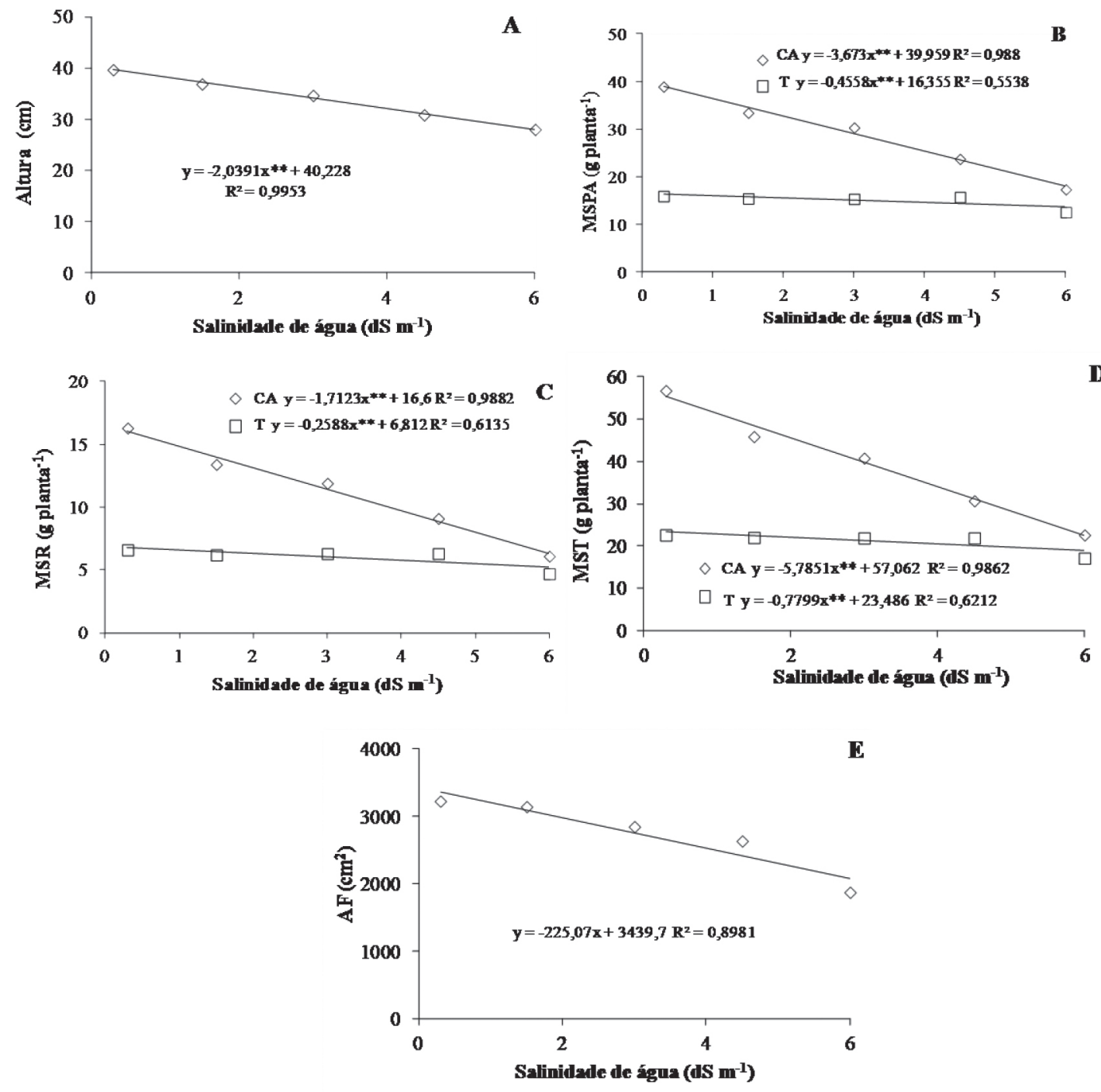

FIGURA 1 - Altura (A), massa seca da parte aérea - MSPA (B), da raiz - MSR (C), total - MST (D) e área foliar - AF (E) de plantas de Morinda citrifolia cultivadas em dois ambientes: céu aberto (CA) e telado (T), em função da presença e ausência de matéria orgânica, aos 110 dias após o início do experimento. Sobral- CE, 2011. 


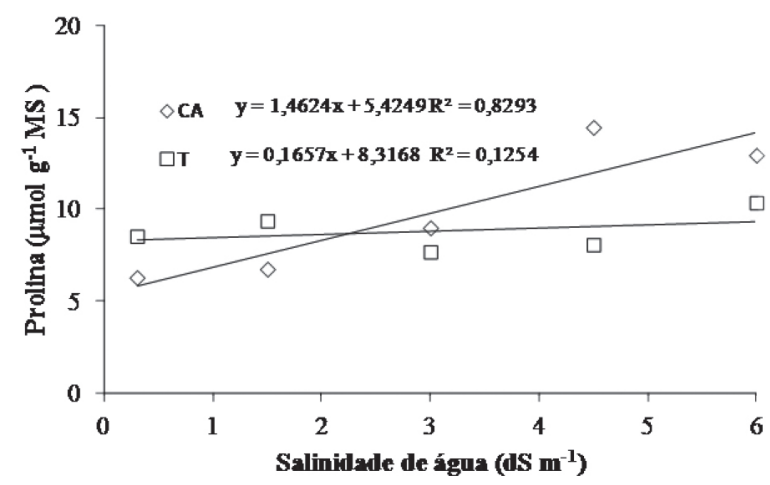

FIGURA 2 - Teores foliares de Prolina em plantas Morinda citrifolia cultivadas em dois ambientes: céu aberto (CA) e telado (T), em função da presença e ausência de matéria orgânica, aos 90 dias após o início do experimento. Sobral- CE, 2011.

\section{CONCLUSÕES}

Plantas sob condição de telado mostram-se mais tolerantes à salinidade, sendo esse ambiente o mais indicado para a produção de mudas de noni sob irrigação localizada com água salobra.

A matéria orgânica não tem efeito atenuante sobre os efeitos deletérios da salinidade em plantas de noni.

O acúmulo de prolina mostra-se um sinalizador de dano causado pelo estresse, visto que os maiores acúmulos ocorrem nas plantas que sofrem maiores reduções no crescimento.

\section{REFERÊNCIAS}

ABDELFATTAH, M. A.; SHAHID, S. A.; OTHMAN, Y. R. Soil Salinity Mapping Model Developed Using RS and GIS-A Case Study from Abu Dhabi, United Arab Emirates. European Journal of Scientific Research, Cairo, v.26. n.3, p. 342-351, 2009.

AMORIM, A. V.; GOMES-FILHO, E.; BEZERRA, M. A.; PRISCO, J. T.; LACERDA, C. F. Respostas fisiológicas de plantas adultas de cajueiro-anão precoce à salinidade. Revista Ciência Agronômica, Fortaleza, v.41, n.1, p.113-121, 2010.

BATES, L.S.; WALDREN, R.P.; TEARE, I.D. Rapid determination of free proline for water stress studies. Plant Soil, Dordrecht, v. 39, n.1, p. 205-207. 1973.
BLANCO, F. F.; FOLEGATTI, M.V.; GHEYI, H.R.; FERNANDES, P.D. Growth and yield of corn irrigated with saline water. Scientia Agricola, Piracicaba, v.65, n.06, p.574-580, 2008.

BRADFORD, M. M. A Rapid and Sensitive Method for the Quantitation of Microgram Quantities of Protein Utilizing the Principle of Protein-Dye Binding. Analytical Biochemistry, San Diego, v.72, n.1-2, p.248-254, 1976.

CAVALCANTE, L. F.; SILVA, G. F.; GHEYI, H. R.; DIAS, T. J.; ALVES, J. C.; COSTA,A. P. M. Crescimento de mudas de maracujazeiro-amarelo em solo salino com esterco bovino líquido fermentado. Revista Brasileira Ciências Agrárias, Recife, v. 4, n. 4, p. 414-420, 2009.

CAVALCANTE, L. F.; VIEIRA, M. S.; SANTOS, A. F.; OLIVEIRA, W. M.;NASCIMENTO, J. A. M. Água salina e esterco bovino líquido na formação de mudas de goiabeira cultivar Paluma. Revista Brasileira de Fruticultura, Jaboticabal, v.32, n.1, p.251-261, 2010.

CHAN-BLANCO, Y.; VAILLANT, F.; PEREZ, A. M.; REYNES, M.; BRILLOUET, J.-M.; BRAT, P. The noni fruit (Morinda citrifolia L.): A review of agricultural research, nutritional and therapeutic properties. Journal of Food Composition and Analysis, New York, v.19, n.6-7, p.645 - 654, 2006.

CHA-UM, S.; KIRDMANEE, C. Remediation of salt-affected soil by the addition of organic matter - an investigation into improving glutinous rice productivity. Scientia Agricola, Piracicaba, v.68, n.4, p.406-410, 2011. 
COSTA, A. B.; OLIVEIRA, A. M. C.; SILVA, A. M. O.; MANCINI-FILHO, J.; LIMA, A. Atividade antioxidante da polpa, casca e sementes do noni (Morinda citrifolia linn). Revista Brasileira de Fruticultura, Jaboticabal, v. 35, n. 2, p.345-354, 2013.

DUBOIS, M. GILLES, K. A., J. K. HAMILTON, P. A. REBERS, AND F. SMITH. Colorimetric method for determination of sugars and related substances. Analytical Chemistry, Washington, v.28, n.3, p.350-356. 1956.

FIGUEIREDO, V. B.; FARIA, M. A.; SILVA, E. L. Crescimento inicial do cafeeiro irrigado com água salina e salinização do solo. Revista Brasileira de Engenharia Agrícola e Ambiental, Campina Grande, v.10, n. 1, p. 50-57, 2006.

HUANG, C.H.; ZONG, L.; BUONANNO, M.; XUE, X.; WANG T.; TEDESCHI, A. Impact of saline water irrigation on yield and quality of melon (Cucumis melo cv. Huanghemi) in northwest China. European Journal of Agronomy, Amsterdam, v.43, s/n, p. 68-76, 2012.

KAVI KISHOR, P.B. S.; AMRUTHA, R. N.; NAIDU, K. R.;RAO, K.R.S.S.; SREENATH, R.A.O;REDDY, K.J.; THERIAPPAN, P.; SREENIVASULU, N. Regulation of proline biosynthesis, degradation, uptake and transport in higher plants: Its implications in plant growth and abiotic stresstolerance. Current Science, Bangalore, v.88, n.3, p.424-438, 2005.

LACERDA, C.F.; CAMBRAIA, J.; CANO, M.A.O.; RUIZ, H.A.; PRISCO, J.T. Solute accumulation and distribution during shoot and leaf development in two sorghum genotypes under salt stress. Environmental and Experimental Botany, Paris, v.49, n.2, p.107$120,2003$.

MARTINS, J. R.; ALVARENGA, A. A.; CASTRO, E. M.; SILVA, A. P. O.; OLIVEIRA, C.; ALVES, E. Anatomia foliar de plantas de alfavaca-cravo cultivadas sob malhas coloridas. Ciência Rural, Santa Maria, v. 39, n. 1, p. 82-87, 2009.
MELO, R. R. de; CUNHA, M. do C. L. Crescimento inicial de mudas de mulungu (Erythrina velutina Wild.) sob diferentes níveis de luminosidade. Ambiência, Guarapuava, v.4, n.1, p.67-77, 2008.

MUNNS, R.; HUSAIN, S.; RIVELLI, A. R.; RICHARD, A. J.; CONDON, A. G.; LINDSAY, M. P.; LAGUDAH, E. S.; SCHACHTMAN, D. P.; HARE, R.A. Avenues for increasing salt tolerance of crops, and the role of physiologically based selection traits. Plant and Soil, Dordrecht, v.247, n.1, p.93105, 2002.

NAZÁRIO. A. A.; GARCIA. G. de O.; GONÇALVES. I. Z.; MADALÃO. J. C.; ARAÚJO. G. L. Crescimento do cafeeiro conilon irrigado com água salina. Engenharia Ambiental: Pesquisa e Tecnologia, Espírito Santo do Pinhal, v.7, n.3, p.178 $-195,2010$.

NIVAS, D.; GAIKWAD, D. K.; CHAVN, P. D. Physiological Responses of Two Morinda Species under Saline Conditions. American Journal of Plant Physiology, New York, v.6, n.3, p.157-166, 2011.

NUNES, J. C.; CAVALCANTE, L. F.; REBEQUI, A. M.; LIMA NETO, A. J. de; DINIZ, A. A.; SILVA, J. J. M.; BREHM, M. A. da S. Formação de mudas de noni sob irrigação com águas salinas e biofertilizante bovino no solo. Engenharia Ambiental: Pesquisa e Tecnologia, Espírito Santo do Pinhal, v.6, n. 2, p. 451-463, 2009.

YEMM, E. W.; WILLIS, A. J. The estimation of carbohydrates in plants extracts by anthrone. Biochemical Journal, Colchester, v.57, n.5, p.508514, 1954. 